\title{
E-Learners' Challenges and Coping Strategies in Interactive and Collaborative e-Learning in Kenya
}

\author{
Rachael Njeri Kibuku' ${ }^{1}$, Daniel Orwa Ochieng ${ }^{2}$, Agnes Nduku Wausi ${ }^{2}$ \\ ${ }^{1}$ Faculty of Computing and Information Management, KCA University, Nairobi, Kenya \\ ${ }^{2}$ School of Computing and Informatics, University of Nairobi, Kenya \\ Correspondence: Rachael Njeri Kibuku, Faculty of Computing and Information Management, KCA University, Nairobi, \\ Kenya.
}

Received: Sep. 8, $2020 \quad$ Accepted: Oct. 11, $2020 \quad$ Online Published: Oct. 14, 2020

doi:10.11114/jets.v8i11.5004

URL: https://doi.org/10.11114/jets.v8i11.5004

\begin{abstract}
Some universities in Kenya have taken up e-learning to flexibly deliver learning and bridge the educational access gap. Despite the benefits that e-learning offers to the e-learners, there are challenges that they must cope with. The aim of this paper is to present the challenges that emerged from a research that was undertaken in two Institutions of Higher Learning (IHLs). It also presents the coping strategies that e-learners used to overcome the challenges. The research used the constructivist version of Grounded Theory (GT) methodology. It used in-depth interviews and participant observations to gather data from the e-learners, e-tutors, e-learning managers and e-learning platforms. Therefore, the research yielded qualitative data which was analyzed using Atlas.ti software. Data was analyzed thematically to establish the patterns of challenges and the equivalent coping strategies. The results are presented using the Gioia technique and the discussion used the vignettes technique from participants in order to preserve their voice. The challenges that emerged relate to: e-content, coursework, internet access, e-learning technology, Information and Communication Technology (ICT) skills and training, interaction and collaboration, personal issues, teaching of Science, Technology, Engineering and Mathematics (STEM) courses and the tutorials. Recommendations on how to tackle these challenges have also been suggested. An understanding of these challenges is important to the e-learning players so that they can adopt interventions to mitigate them and hence improve interaction and collaboration. The results presented in this paper are part of the larger research whose main objective was to develop an e-learning theory for interaction and collaboration.
\end{abstract}

Keywords: e-learning, grounded theory, interaction, collaboration, challenges

\section{Introduction}

The past two decades have witnessed a heightened demand for higher education in Kenya which has resulted in an increase in the number of Institutions of Higher Learning (IHLs) in the country. By November 2017 there were 31 public universities with six affiliate colleges, 18 private universities with five affiliate colleges and 14 universities in both categories operating with letters of interim authority (Commission of Higher Education [CUE], 2017). However, the increased number of universities has not been sufficient to satisfy the high demand for higher education in the country hence widening the educational access gap. Some universities have resulted in adopting e-learning to bridge this gap (Nyerere et al., 2012). e-Learning is particularly attractive to the adult learners who are seeking to improve their academic qualifications aimed at career advancement. Adult learners who are already in employment require a flexible way to access education while they continue working to support their families. Besides the flexibility, other benefits of e-learning include: learning at e-learners' own time and pace, allowing stay-at-home mothers to pursue education that otherwise would not have been possible, combining work with studies among others.

\subsection{Problem Statement}

Interaction and collaboration are the hallmark of social learning (Anderson \& Dron, 2011). The key benefit of social learning is that it allows the learners to learn and discover knowledge in their groups. However, this is not the case with e-learning in IHLs in Kenya because the e-learners are confined to solitude during the learning process with little or no interaction and collaboration (Nyerere et al., 2012 \& Muuro et al., 2014). Despite the geographical distance between the e-learners and e-tutors, e-learning should be designed and delivered in a manner that encourages interaction and collaboration. Therefore, this research sought to know the challenges that hindered the desired interaction and 
collaboration among the e-learners and between the e-learners and their e-tutors. It also sought to know how the e-learners coped with those challenges. An understanding of these challenges is important so that e-learning players can adopt interventions to mitigate them.

\subsection{Research Questions}

The research was guided by the following questions:

(1) What challenges do the e-learners face in interactive and collaborative e-learning environments?

(2) How do the e-learners cope with the challenges?

\subsection{Literature Review}

This section presents the pedagogical e-learning models, the theoretical background of interactive and collaborative elearning and the status of interactive and collaborative e-learning in Kenya.

\subsection{1 e-Learning Pedagogical Models}

e-Learning pedagogical models include the particular designs of deploying technology to support e-learning pedagogy (Aparicio et al., 2016). There exists three e-learning pedagogical models namely: open learning, distributed learning and learning communities (Dabbagh, 2005). Open learning is an e-learner-oriented model that emphasizes on meeting the elearners' individual needs. It flexibly delivers e-learning services such as evening or part time courses, short courses, workshops, conferences, seminars, certificate, diploma and degree programs" (Aparicio et al., 2016 \& Dabbagh, 2005) by use of knowledge portals, asynchronous learning networks, knowledge networks, tele-learning and virtual classrooms (Dabbagh, 2005). Distributed learning [also known as ubiquitous learning] is education delivered to various locations at any time using telecommunication technologies (Aparicio et al., 2016). An example of distributed learning is Computer Supported Collaborative Learning (CSCL) which is centered on e-learner interaction and collaboration (Janssen \& Bodemer, 2013). It uses e-mails, chatrooms, discussion fora, video and audio conferencing. Distributed Learning activities are carried out at self-appointed times and they are self-paced (Dabbagh, 2005). Learning Communities (LCS) are groups of e-learners with the same learning agenda participating in socio-cultural activities in projects within their discipline (Aparicio et al., 2016 \& Dabbagh, 2005). LCs offer social and informal academic support to the participants with a focus on learning rather than teaching (Dabbagh, 2005).

\subsubsection{Theoretical Background}

There are three relevant theories in interaction and collaboration namely: constructivism, social constructivism and connectivism. Constructivism underpins 'active learning' concept (Kalpana, 2014 \& Bognar, 2016) that advocates for participation in the learning process and critical thinking aimed at gaining and expanding learners' understanding rather than assimilating information from tutors (Amineh \& Asl, 2015). To e-learning, constructivism implies that e-tutors should offer online interactive tasks to boost co-operative learning. It also implies that e-learning resources should be designed to include collaborative tasks (Alzaghoul, 2012). The corresponding e-learning pedagogical model for constructivism is distributed learning (Dabbagh, 2005). Social constructivism introduced the concept of 'social presence' of e-learners and e-tutors in the learning process. It also emphasized the 'situative learning' concept, hence its implication to e-learning is that e-tutors should create e-learning experiences that are similar and familiar to the e-learners' real-life experiences (Amineh \& Asl, 2015). The corresponding e-learning pedagogical model for social constructivism is a blend of distributed learning and learning communities (Dabbagh, 2005). Connectivism emphasized the use of contemporary technologies to achieve social interconnectedness among e-learners and between e-learners and e-tutors. It postulates that knowledge is situated in a web of Learning Communities (LCs), which are groups of learners with similar learning agenda and interests (Kop \& Hill, 2008). Its implication to e-learning is that learning activities and resources should be designed to include co-operative groups of active members consisting of both e-learners and e-tutors (Foroughi, 2015). The corresponding e-learning pedagogical models for connectivism are learning communities and social networks (Dabbagh, 2005).

\subsubsection{Interaction and Collaboration in e-Learning in Kenya}

Learning is made more efficient by learners actively participating in groups and discovering knowledge on their own through real-life experiences (Wu et al., 2010). However, according to Nyerere et al. (2012) the Learning Management Systems (LMS) used by IHLs in Kenya are content-centered. They only employ asynchronous mode of delivering learning materials but lack learner-learner and learner-tutor interaction thus encouraging passive learning. The e-tutors use these LMSs to post the e-content and coursework; e-learners in turn access them and study them individually since the design of the e-content does not emphasize interactivity and group working (Mwaniki et al., 2016). According to Nyerere (2016) this problem was attributed to lack of e-tutor training in interactive e-content design. The interactive and collaborative tools in the LMSs are either not in use or their use is minimal. A study by Muuro et al. (2014) established that many e-learning initiatives are characterized by lack of e-learners' collaboration and social interaction. This study further found out that e-tutors failed to 
initiate collaborative activities among the e-learners with $41.3 \%$ of the respondents citing that their e-tutors did not engage them in collaborative tasks. In situations where e-learners engaged in collaborative activities, $47 \%$ cited lack of feedback from the e-tutors as a big challenge; a problem that Nyerere et al. (2012) and Mwaniki et al. (2016) attributed to lack of training of staff and low motivation on the part of the e-tutors. Further, according to Nyerere et al. (2012) and Nyerere (2016) the e-tutors who facilitate the delivery of e-learning are the same tutors teaching in the conventional learning thus they lack the time to initiate interactive and collaborative activities.

\section{Method}

The main objective of the research was to develop a theory, therefore it adopted the constructivist paradigm. It also adopted the pragmatic philosophy that involved the researcher interpreting the data obtained from in-depth interviews and participant observations. Finally, it adopted the induction approach where the engagement with theory happened after the research. The research employed the qualitative approach to data collection and analysis. It used the Grounded Theory (GT) methodology that is applicable when extant theories fail to adequately explain a phenomenon (Walsh et al., 2015 and Wiesche et al., 2017). GT was favored because it's procedures allowed the researcher to flexibly examine the experiences of e-learners, e-tutors and e-learning managers in order to develop broad explanations leading to the development of the substantive e-learning theory (Gentles et al., 2015). The research used the constructivist version of GT (Charmaz, 2014) because the intention was to construct the theory from the researcher's interactions with the elearning participants and their perspectives on e-learning. Thus, the researchers' role was somewhere between the participant-observer and passive-observer.

\subsection{Research Design}

Some GT versions advocate deferring the reviewing of literature until after the theory has been developed to avoid contaminating it with preconceptions from existing literature and theories. However, this research adapted the constructivist GT to include a brief review of technical literature at the beginning (see figure 1) as advised by Charmaz (2014). This was to establish the theoretical gaps in existing theories, establish the provisional concepts and formulate the research questions that guided the research.

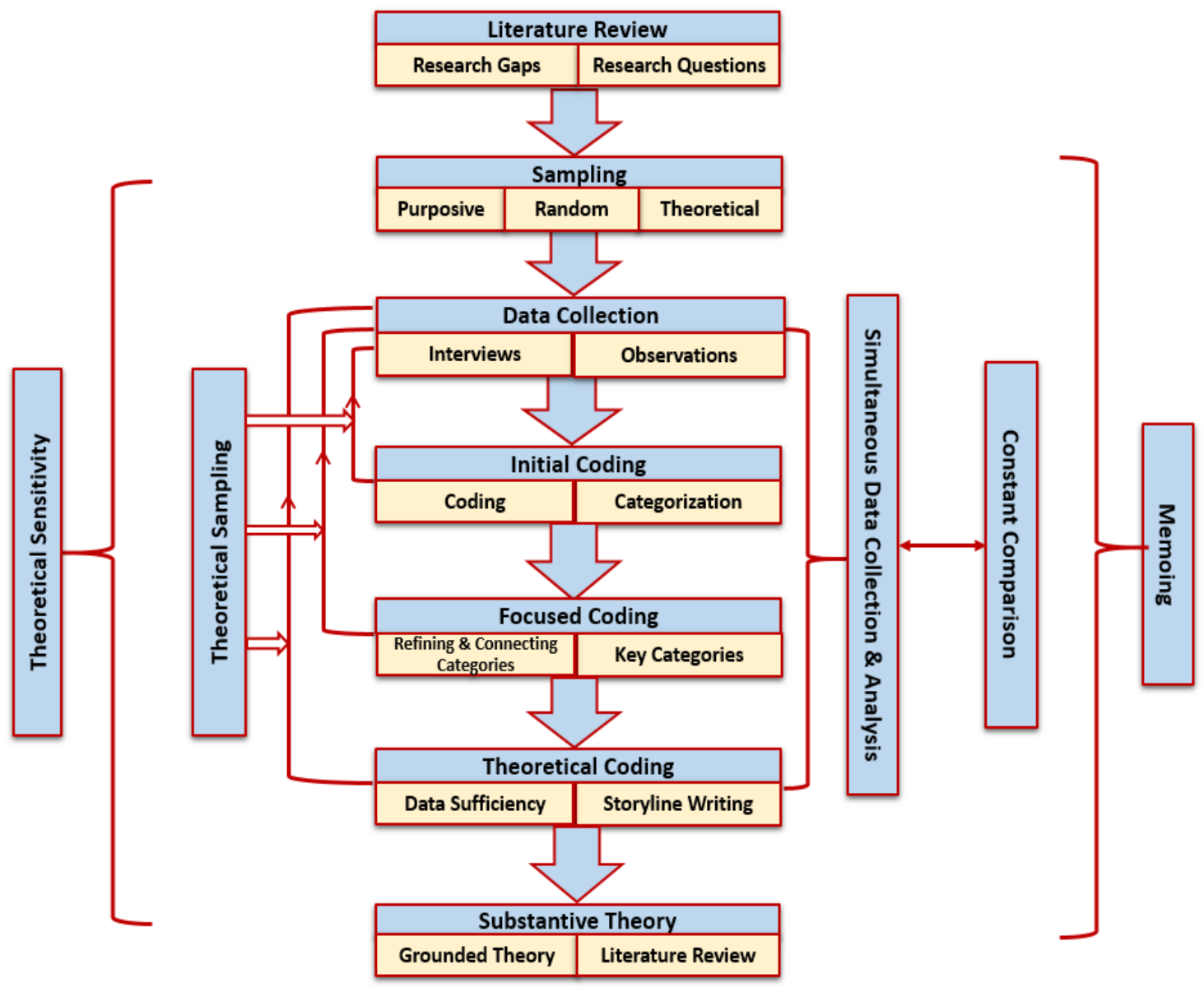

Figure 1. Research design (adapted from Charmaz, 2014 and Chun-Tie et al., 2015) 


\subsection{Preliminary Study and Data Collection Tools}

A preliminary study was conducted before data collection by use of observation method to gain an understanding of the real situation on the ground. This entailed a survey of the characteristics and activities such as the design of the LMSs, exchanges among e-learners and their e-tutors, frequency of such exchanges, interaction tools used, e-content exchanged, among any other observable characteristics and activities. The preliminary study shaped the research by establishing the variability of the survey sample and assisted the researcher to reflect and focus on the data needed and from where to get it. The results of this survey guided the design of the interview schedules.

\subsection{Data Collection Procedures and Ethical Consent}

The research sought for data collection authorization from the ethics and review board and other relevant research authorities. These permits were then presented to the respective universities' research and postgraduate schools to seek approval for data collection from their e-learning programs. Thereafter, the participants were called by the researcher to request for an interview, upon which when granted, a date was scheduled. At the beginning of every interview, the purpose and the terms of the interview were explained and the letter of informed consent presented to the participants.

\subsection{Sampling Procedures}

The research involved two Universities in Kenya anonymously coded as University-1 and University-2, that were chosen purposively because they possessed the variability of the data needed. The research used in-depth interviews and participant observation to collect data which are admissible methods in line with GT principles (Aldiabat et al., 2018). In-depth interviews allowed probing for more data (Miles et al., 2020). Observations were used to corroborate and triangulate the data received from the interviews (Aldiabat et al., 2018). 35 distant e-learners were interviewed who were selected using a combination of theoretical and random sampling. 16 e-tutors also participated, six chosen purposively because they were managers who were well-informed in the e-learning matters and the remaining ten were selected using a combination of theoretical and random sampling. However, the e-tutors' perspectives in this article are only meant to corroborate the e-learners' challenges. The interviews were conducted in iterations; the first iteration was a face-to-face session that lasted between one hour to $1 \frac{1}{2}$ hours. Data was captured by note taking and audio recording. Where necessary, follow-up data collection iterations were conducted using member-checking technique via telephone conversations to corroborate previously collected data, clarify issues and gather more data. By the $30^{\text {th }}$ interview the trends from the data started to stabilize. Five more interviews were conducted to see if any new data or trends would emerge after which data collection ended and theoretical saturation was attained; a point at which the data obtained was sufficient for the analysis desired.

\subsection{Data Collection, Analysis and Memo Writing}

The activities of data collection, analysis and memo writing were carried out concurrently. A data "inspection cycle" (Kalpokaite \& Radivojevic, 2019, p. 50) was carried out before analysis that involved transcribing, cleaning, identifying gaps and ordering the data into a logical flow. Data was then entered in Atlas.ti for analysis. Initial coding started with the first interview's data and memo writing started immediately. The subsequent interviews were conducted using random and theoretical sampling to corroborate the previous interviews' data and identify divergent views. This process combined with constant comparison of the previously obtained data continued up to the $35^{\text {th }}$ interview. From initial coding, the process progressed to focused coding and then to theoretical coding. Initial coding established the challenges as well as the coping mechanisms from the data. Focused coding involved categorizing the identified initial codes into themes after iterative data collection and analysis. Theoretical coding involved lifting the analyzed data from its face-value meaning to a conceptual level relating it with the emerging category of 'challenges in interactive and collaborative e-learning environments' after iterative data collection and analysis. The story line of the challenges was then documented. The research used thematic analysis to establish themes/patterns of commonality and recurring challenges from the data (Miles et al., 2020). The results were presented using Gioia and vignettes techniques (Reay et al., 2019).

\subsection{Results Validation}

The robustness of the results rest on four premises, first, the use a survey of two universities yielded comparable results. Second, the combined use of interviews and observations ensured triangulation. Third, although the participants were theoretically sampled they were also randomly identified thus eliminating subjective bias. Fourth, the involvement of etutors and managers triangulated the findings.

\section{Results}

The challenges identified were categorized into nine themes which together with their coping mechanisms are summarized in figure 2 . 


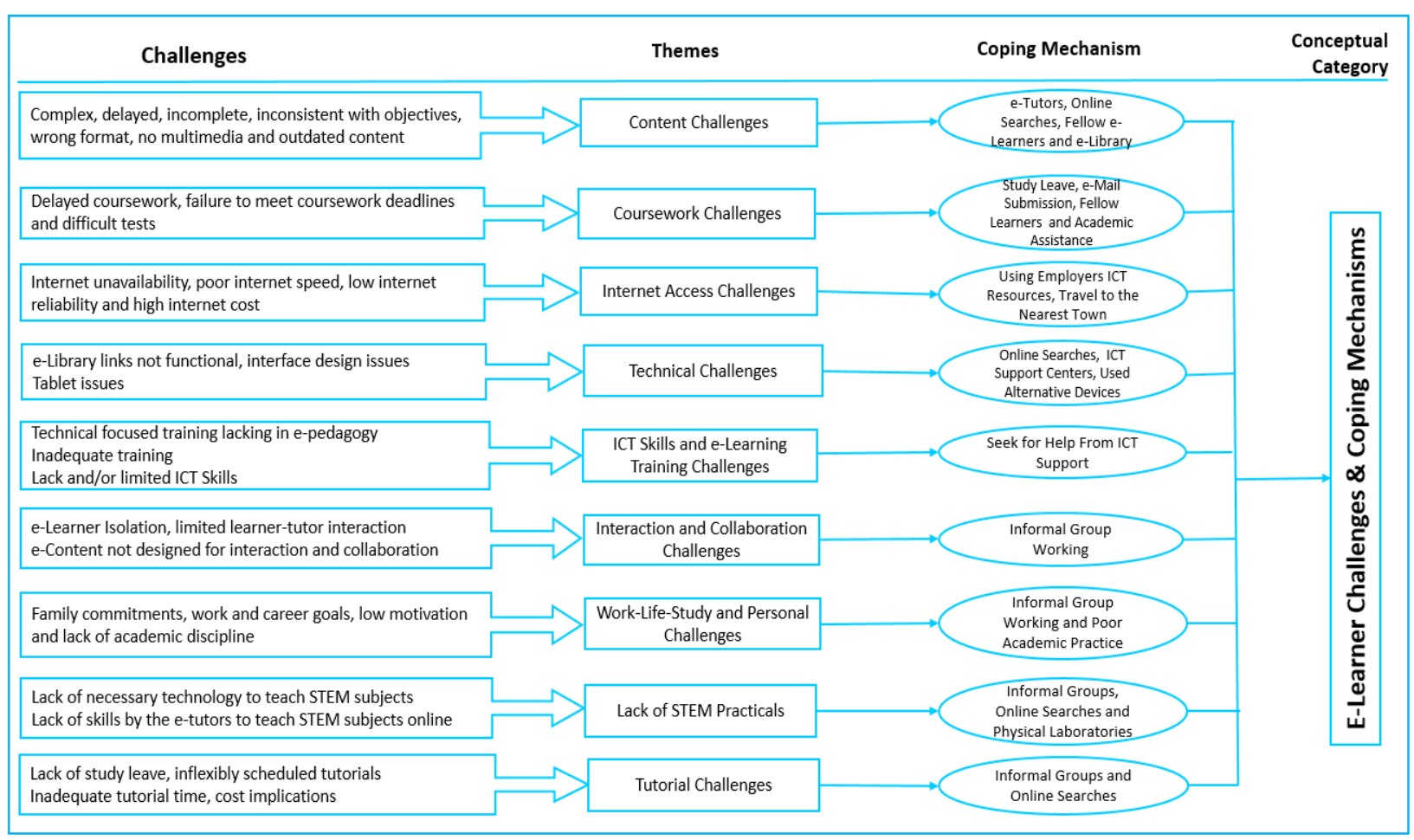

Figure 2. e-Learner challenges, themes and coping mechanisms

\section{1 e-Content Challenges}

The persistent e-content issues included: complex, delayed, incomplete, inconsistent with objectives, wrongly formatted, outdated, lacking in multimedia and interactive activities. This was corroborated by observation of the e-content uploaded on the LMSs. Depending on the challenges the e-learners coped by adopting a variety of strategies. Of importance to this study was complex e-content where all participants alluded to encountering e-content that was difficult to understand during their personal studies. To cope with this challenge, they sought for help from various sources as follows:

1) $40 \%$ of the participants contacted their e-tutors over complex e-content.

2) $88.6 \%$ of the participants turned to online sources specifically Google and YouTube.

3) $77.1 \%$ of the participants turned to fellow e-learners in their small informally [outside the LMS] constituted groups.

4) $14.3 \%$ of the participants sought e-content help from the e-library.

\subsection{Coursework Challenges}

Three persistent coursework challenges were identified. Firstly, there were delays in uploading the coursework leaving insufficient time which leads to cognitive overload when it happens towards the end of the semester. To cope with delayed uploading of e-content, many participants took leave from work to do the coursework in the short notice. One participant said, "it disorganizes me because I have to take leave to do the coursework, which I had time to do earlier should it have been uploaded in good time". Secondly, there were difficult tests and assignments, where $34.3 \%$ of the participants alluded to seeking academic assistance from fellow e-learners and external tutors but not designated e-tutors. Others engaged academic assistants at a fee. One participant said, "in the case of the difficult assignments I went to another tutor from a different university and I paid him". $43.75 \%$ of the e-tutors corroborated this finding by reporting that they suspected someone else did the coursework on behalf of the e-learners. The e-tutors justified their suspicion by the poor performance in the examinations compared to coursework. One e-tutor explained, "they tend to do well in the coursework but in the examinations they perform poorly". Thirdly, some participants indicated that they lacked the time to do the coursework. One participant said, "due to the pressure of work I get surprised there is an assignment that needs my attention". To cope with this challenge some participants submitted coursework via e-mail since they were time-barred by the LMS while other turned to academic assistance.

\subsection{Internet Access Challenges}

Three internet access issues persisted, first, there was lack of internet availability in some rural and remote areas of the country. To cope with this challenge, participants travelled to the nearest town to access the internet. One participant said, 
"I had to travel for about $40 \mathrm{kms}$ to access internet and submit the coursework". Second, though the e-learners had invested in internet at their homes, majority cited high cost as a major problem. $88 \%$ of the participants in formal employment used their employers' ICT resources to cope with the prohibitive internet access cost. One participant said, "the cost of downloading reading materials, submitting coursework and searching for extra reading materials online, is very high for me". Participants that were not in formal employment had to bear the high internet access cost at home while a minority visited cybercafés. Third, those participants who used their employers' internet indicated that the internet connection at home was poor hence coped by using their employers' internet that was [very] fast and reliable. One participant said, "internet at work is very fast and reliable, no waiting for things to download or upload".

\subsection{Technical Challenges}

Three technical issues persisted, first, some e-library links to resources were not functional, which was corroborated by the observation of the e-library. To cope with e-library challenge, majority went online elsewhere to search for equivalent materials. Others did not know how to use the e-library to locate needed resources. To cope with this challenge, they contacted the ICT support centers to help them access the e-library. Second, although majority rated the LMSs as having good usability and affordance, some complained that the interface was text-based and preferred a Graphical User Interface (GUI). As a result, they had challenges using and navigating the LMS especially at the beginning. To cope with user interface design issues, they called the ICT support centers. Third, although the e-learners were expected to acquire their own ICT devices, the universities issued them with a tablet upon enrolment since not all e-learners were able to acquire or access these devices. This tablet turned out to have the following challenges:

1) The increase of $4 \mathrm{G}$ smartphones in the market rendered the tablet redundant hence some participants abandoned its use in favor of the smartphones.

2) The $3 \mathrm{G}$ tablets issued earlier were rendered useless when other accompanying technologies changed to $4 \mathrm{G}$, making the old tablets very slow and sometimes incompatible with the upcoming technologies. The participants issued with $3 \mathrm{G}$ tablets accessed the portal on other devices.

3) In University-2 the tablet was locked to e-learning use only. Furthermore, it had to be returned to the university every beginning of a semester for loading of new e-content. In case of failure or breakage it had to be repaired from the university's ICT support center; a requirement that the participants found cumbersome. Some indicated that they had set it aside and continued to access the LMS on other devices. However, University-2's tablet concept was ideal for e-learners in remote places without [or with intermittent] internet access such that they always had their e-content available offline.

4) The size of the tablet's internal memory was limiting, making it difficult to run heavy application software needed in STEM-oriented courses. In such cases, the participants acquired laptops or desktop computers.

\subsection{ICT Skills and e-Learning Training Challenges}

Three challenges persisted; first, $61.3 \%$ of the participants who attended the induction training lamented that it was not adequate to master all the features of the LMS. e-Learning managers blamed inadequate training on lack of sufficient resources to run a fully effective training program. Besides the induction training, the regularly planned refresher trainings were poorly attended. One manager lamented, "when I call them for refresher training they fail to attend so they don't have the skills". Second, lack of and/or limited ICT skills was a common challenge among the older participants. To cope with these two challenges, participants sought for technical help from the ICT support centers and from user manuals available in the LMSs. Third, $93.5 \%$ of the attendees indicated that the induction training mainly focused on the technical aspects, with limited e-pedagogy aspects. One participant said, "the induction only concentrated on technical aspects......instead it should have concentrated in helping us to understand everything that e-learning entails". To cope with this challenge they sought for support from the e-learning help-desk.

\subsection{Interaction and Collaboration Challenges}

Two challenges persisted, first, all participants alluded to suffering isolation in e-learning. One participant said, " $e$ learning is a very lonely way to learn. I am alone like lone ranger". The participants indicated that their e-tutors did not initiate collaborative activities. From the observations, the design of the e-content, tests and practicals lacked collaborative activities thus encouraging individualism further isolating the e-learners. Further, although the LMSs in use in both universities have collaborative learning tools, all the participants indicated that they were not trained on how to use them. One manager corroborated this finding saying, "we have not emphasized on group working in the training and once it is left out it is not practiced by the e-learners and e-tutors". To cope with isolation, $88.6 \%$ of the participants formed small informal groups amongst themselves from where they drew moral support, exchanged ideas, solved problems, resolved complex e-content and performed practicals (for STEM-based participants). Second, $51.4 \%$ of the participants lamented the lack and/or limited learner-tutor interactions which was blamed on e-tutors' unavailability as they doubled up as 
conventional learning tutors and e-learning tutors, making it hard for them to find time to interact with their e-learners. The observation of the LMS revealed that interactions tools provided for learner content support such as the discussion fora and chats were mainly unused. Resolving complex e-content issues was one important reason why the e-learners desired to interact with their e-tutors. In the absence of e-tutors' content support or when the support is not adequate the e-learner's turned to online sources like Google and YouTube to seek for e-content support.

\subsection{Personal-Related Challenges}

Three personal issues persisted, first, $94.3 \%$ of the participants were already in employment hence pursuing promotions and career goals. One e-learner said "I am seeking for a degree so that I can get the promotion that has been elusive". $22.9 \%$ of these employed e-learners also indicated that they had family commitments. This lead to work-life-study balance challenge. One participant said, "There is always something about work, social life and family coming up when I am supposed to be reading". To cope with this challenge some participants either studied while at work during tea and lunch breaks, after work or late into the night after family responsibilities. Another participant said, "I am at work all day and being a mother I have study at night when I should be resting". Second, lack of academic discipline and commitment to study was observed in $40 \%$ of the participants. The indicators were failure to meet coursework deadlines, participate in online discussions and study their notes. One participant said, "ideally I don't know what happens when one enrolls as an e-learner, the subconscious does not register that one is student". $56.3 \%$ of the e-tutors observed this academic indiscipline with one saying, "some either do not submit their coursework at all or they delay to submit". To cope, such participants rushed to do things the last minute and others submitted coursework after the deadline via e-mail. Third, $14.3 \%$ of the e-learners suffered from low motivation caused by isolation and other challenges. One participant said, "there are so many challenges to overcome with little support... which serve as motivaion killers". To cope with this challenge, they reached out to each other for moral support in their informal groups as they tackled the challenges together.

\subsection{STEM Practicals' Challenges}

$51.4 \%$ of the participants were enrolled in STEM courses that required practicals, which were mainly lacking and in rare occasions they were undertaken during tutorials. One participant decried, "I was surprised why a science-based course which involves a lot of practicals was offered online yet the university has no capacity". Lack of practicals was occasioned by two challenges, first, there lacked necessary technologies to teach practicals online. One manager lamented, "the elearning infrastructure is not mature enough to allow online teaching of practicals". Second, there lacked funds to afford the necessary technologies and training. One manager said, "the needed specialized technology is expensive and training is costly". Thus the e-learners used the following coping strategies:

1) $15.8 \%$ did the practicals in their informal groups.

2) $36.8 \%$ did practicals with their e-tutors during the tutorials. However, the tutorial time is hardly enough. One elearner said, "the practicals are only done during the tutorials and that time is limited so in a unit with so many topics and equivalent practicals I end up doing only one practical".

3) All the STEM participants sought for practical help from online tutorials on YouTube.

\subsection{Tutorial Challenges}

Two tutorial challenges persisted, first, $65.7 \%$ of the participants had never attended tutorials. Absenteeism was attributed to:

1) Failure to secure study leave from their respective employers since majority of the e-learners were in employment.

2) Prohibitive cost involved in attending the tutorials which include transport, food and accommodation.

3) Inflexibly scheduled tutorials where majority of the e-learners argued that the timing did not fit in their worklife schedule.

Second, all the participants who attended the tutorials attested to the tutorial time inadequacy. One participant wondered, "how do we handle a whole semester's work in 3-4 hours?". The coping mechanisms employed by all was the use of online tutorials.

\section{Discussion}

\section{1 e-Content Challenges}

e-Content is the learning materials uploaded by the e-tutors that include: course manuals, course outlines, lecture notes, tests/coursework and reference materials. The major e-content challenge was complexity which was further compounded, in some situations by outdated, incomplete, delayed, inconsistent, wrong format and e-content lacking in multimedia. These issues are traced back to the design of the e-content. Raspopovic et al. (2014) defined the quality metrics of the e- 
content uploaded on the LMS by the e-tutors to include: accuracy, completeness, inclusion of multimedia, clarity, ease of understanding, presentation, organization and up-to-date e-content. According to e-learning managers the e-content challenges stemmed from inadequate e-tutor training in e-content development despite there being e-content development units in the respective universities. One manager said, "it's not enough to train them initially and trust that they learned everything they are supposed to know about e-tutoring and though there is a refresher training where e-content design is addressed, majority do not attend". Despite the e-tutors being the creators and originators of the e-content, it turned out that majority of the e-learners did not contact their e-tutors over complex e-content citing e-tutors' unavailability as they were busy teaching in conventional learning. This finding was corroborated by e-learning managers who confirmed that the universities do not have dedicated e-tutors. This is consistent with the findings by Serdyukova and Serdyukov (2014) who reported that in many IHLs, majority of conventional learning tutors are turned into e-tutors and thus are pressed by time to carry out e-tutelage activities effectively. The minority of the e-learners that reached out to the e-tutors for econtent help indicated that the help was limited, delayed or sometimes not forthcoming. One participant said, "Some units are very difficult to study on my own and when I try to get the e-tutors they are busy in face-to-face classess and when I get them it's for very little time". Hence, the e-learners turned to alternative sources of e-content help such as Google and YouTube. This finding is in line with connectivism which postulates that knowledge is stored in many places including nodes/computers in the Internet (Foroughi, 2015). However, although the e-tutors were not opposed to seeking e-content help from online sources majority of them were concerned about the validity of the e-content found online thereby cautioning the e-learners to verify it with their e-tutors and validate it against the course outlines. One e-tutor said, "the e-content and knowledge from online sources need to be authenticated by their e-tutors as fit for their academic consumption. Besides these online tutorials in YouTube may not be within the scope of the curriculum because they may be too shallow or may go too far deep for the e-learners 'level". Further, to cope with e-content challenges the e-learners formed small learning groups where they communicated via WhatsApp social media platform which boosted interaction and collaboration as advocated for in constructivism and connectivism. In this case, fellow e-learners and e-tutors are nodes in which knowledge is stored, retrieved and shared among the members of the cooperative learning group (Foroughi, 2015).

\subsection{Coursework Challenges}

The challenges of delayed e-content and coursework was attributed to lack of dedicated e-tutors hence e-learning becomes secondary to conventional learning. One e-tutor said, "the e-learners get forgotten by the e-tutors because they are not here in campus on a daily basis". Delayed coursework overwhelms the e-learners when it is availed later in the semester and also ceases to be continuous assessment. One participant said, "it fails to be continuous when it comes so late". In coping with difficult coursework some e-learners sought for academic assistance from multiple sources which is in line with connectivist theory that stipulates that knowledge is stored in multiple places and hence they should know how to locate it. However, academic assistance becomes a malpractice that raises ethical issues when payments are involved (Olcott et al., 2015). Further, due to the readily available online e-content the e-tutors lamented that some e-learners engaged in plagiarism when doing coursework. One e-tutor said, "they copy and paste from google and they do not read, understand, filter and then possibly internalize the information they get online". These results are consistent with the findings by Busikova and Melicherokova (2013) who reported that e-learning presents the e-learners with more opportunities for academic dishonesty and fraud, making it easier to cheat in online tests and assignments than in faceto-face tests. To curb the plagiarism problem, this research recommends that e-tutors should design tests and assignments following constructivism and connectivism proposals based on cases and scenarios from e-learners' context and experiences.

\subsection{Internet Access Challenges}

Unavailability, poor quality and high cost of the internet hindered the efficiency with which e-learners undertook their elearning activities. Kenya has a huge urban-rural digital divide when it comes to vital ICT Infrastructure distribution (Ndung'u et al., 2019; Government of Kenya [GOK], 2019). Participants residing and/or working in the rural/remote areas experienced network availability and connection challenges, hence found it difficult to access the portal, download the notes, submit assignments and participate in chats and forums. To address the internet access issues majority of the elearners used their employers' ICT resources which raises ethical issues, with the following foreseeable ramifications:

1) Failure to manage work-life-study boundaries especially when they take time off from the employer to study. This amounts to theft of employers' man-hours (Romero, 2011).

2) Employers' information security is likely to be compromised once the e-learners access sites outside the organization which poses security threats.

3) Misappropriation of organizational ICT resources whose use amounts to theft since there is no compensation to the employer. 


\subsection{Technical Challenges}

Inadequate and/or lack of technical skills of both the e-learners and e-tutors emerged as a problem. Technical challenges were blamed on two problems; first, there was lack of funds to roll out an effective e-learning training program leading to inadequate skills. Therefore, there is need for individual institutions to increase their capacity building budget in order to upscale e-learning training. Second, the on-campus trainings experience e-learners' apathy due to their unavailability. This can potentially be resolved by virtual trainings that are flexibly planned in consideration to the e-learners' commitments. Technology evolution emerged as a technical challenge, where technologies of the past are quickly replaced by the emerging ones. Technology evolution has implications on the interoperability, compatibility and cost of the device requirements for e-learners as observed from the tablet story. This is in line with the findings by Gros and García-Peñalvo (2016) which revealed that although the inevitable technological changes improve the delivery of e-learning, they have consequences on both the e-learners and institutions adopting e-learning technology.

\subsection{ICT Skills and e-Learning Training Challenges}

The induction mainly focused on technical training. Previously, Tarus et al. (2015) and Mwaniki et al. (2016) had reported that e-learning induction training only focused on the functionality of the LMS with no e-pedagogy which is more important since it enables the e-learners to function in the entirely new e-learning environment. However, this research observed a slight improvement where participants indicated that there were limited pedagogical aspects included in the training. Therefore, there is need for a balance between technical and pedagogical training. It was also observed that the technical focused induction was inadequate, hence this research recommends that it needs to be supplemented with virtual training to address the inadequacy.

\subsection{Interaction and Collaboration Challenges}

Islam et al. (2015) had recommended that e-tutors should maintain a daily, continuous online presence on the discussion fora and chats to control and manage discussions, answer questions and provide feedback. However, this research observed that there was limited and/or lack of learner-learner and learner-tutor interactions. This was blamed on two challenges, first, the e-tutors were time constrained to initiate interactive and collaborative activities by use of the interaction tools provided on the LMS, because they were overloaded as they teaching in both conventional learning and e-learning. Second, the e-tutors as well as the e-learners lacked training in the use of collaborative learning tools which denied both parties the intended benefits of collaborative learning advocated for by constructivism and connectivism. Muuro et al. (2014) had earlier observed that e-learning initiatives in IHLs lacked learner-tutor interaction and collaboration. Therefore, this research recommends that IHLs should engage dedicated e-tutors to improve delivery of elearning.

\subsection{Work-Life-Study Challenges}

There was a constant conflict between study and personal responsibilities such as work, career goals, social and family commitments which resulted in work-life-study challenges. Interactive activities on chats and discussion fora which are planned to take place in the evenings, conflict with e-learners' family commitments, especially for young parents who took up e-learning because it fits studying around family. Work-life-study challenges also caused some e-learners to fail to meet coursework deadlines and attend the tutorials. Further, failure to have an appropriate work-life-study balance also caused low motivation levels. Romero (2011) observed that e-learners get overwhelmed when they fail to balance these three aspects. However, despite the work-life-study challenges, career goals emerged as motivation to pursue their studies since majority were looking for work promotions. Cercone (2008) argued that e-learners are highly motivated in carrying out their e-learning activities by factors such as work promotion and job satisfaction.

\subsection{STEM Practical Challenges}

The teaching of STEM-based subjects in e-learning is a failed promise in IHLs in Kenya. Besides the lack of necessary technology and expertise, there is an assumption by universities' management that because majority of these e-learners had an earlier training they do no need the practicals since they already have those skills and experience. One manager said, "usually many of the e-learners already have a career that they are advancing so they are not totally new to these things since they have some experience". This argument is largely true because majority of the participants were seeking career progression after having an earlier qualification at the diploma or undergraduate level. However, this research found some exceptions, e-learners fresh from high school without any earlier training and hence disillusioned by lack of practicals. One participant said, "I know many students who had enrolled in the science subjects but left and others transferred to humanities due to lack of practicals". This was corroborated by some e-tutors who had reservations about online teaching and learning of STEM subjects. One e-tutor asked, "If our e-learners fail in the non-STEM courses, what happens to the STEM-based subjects which are practical in nature?'. This perception that e-learning is more suited and applicable to social sciences than STEM subjects has caused many STEM learners to prefer conventional learning over 
e-learning (Arkorful \& Abaidoo, 2014). While it is true that non-STEM-based e-learning has been around longer than STEM-based e-learning, it is possible to teach STEM-based subjects online (Bhukuvhani et al., 2012). One manager said, 'in the teaching of STEM-based units we could do better by simulation, videos, animations, having more interaction sessions and more training'. From the research the following strategies of improving the teaching and learning of STEM subjects were suggested.

1) Pedagogical training for both e-tutors and e-learners on how to teach and learn practicals online.

2) Technical training of the e-tutors in order to be able to use the technology and pass the practical skills.

3) Acquisition of the specialized STEM tutoring technologies and technical facilitation in terms of facilities for the e-tutors.

4) Availing of funds to offset the aforementioned constraints in form of a budget.

\subsection{Tutorial Challenges}

Tutorials are the face-to-face interaction sessions between the e-learners and e-tutors. They are planned to happen either during the weekdays for a week or a weekend depending on the university concerned. Tutorials help to bridge the physical and psychological distance between the e-learners and the e-tutors (Kee, 2020). They also help to address the challenges that the e-learners have been experiencing when learning alone. However, many e-learners were not able to attend them due to work and family commitments, cost implications and inflexible tutorial schedules. For those who attended, time was a constrain for all the activities lined up. Thus, tutorials ended up being crash programs that exerted undue pressure on the e-learners as the e-tutors tried to recap and revise everything covered [or to be covered] over the entire semester. However, there are e-tutors and e-learners who felt that the tutorial time was adequate if both parties have diligently done their part over the semester. One e-learner reported, "if one has covered the syllabus well, then he/she will see things flow very well in the tutorial. If not, by attending the tutorial, one will be mixed up and confused all the more than if he/she had not attended". Due to the varied tutorial challenges this research recommends the use of online tutorials to address the limited learner-tutor interaction.

\section{Conclusions and Recommendations}

This article has elucidated the various challenges that e-learners experience while undertaking their studies and their coping strategies. It has also presented the causes and effects of these challenges as well as the extent to which they hinder the full realization of the benefits of interaction and collaboration. Key among these challenges is the inadequate and/or lack of ICT infrastructure in the country especially in the rural and remote areas as well as high cost and poor quality of the internet. Other challenges relate to e-content which were traced back to e-tutors' inadequate training on e-content development. Limited e-learner training resulted in inadequate ICT and e-learning skills. Inadequate ICT and e-learning skills in turn caused limited interaction among e-learners and between e-learners and e-tutors. Lack of dedicated e-tutors caused them to be overloaded with face-to-face teaching as well as e-tutoring which left little time for interacting with their e-learners. Work, career goals, social and family commitments led to challenges in work-life-study balance. Finally, limited and/or lack of practicals in STEM courses disillusioned the e-learners. This research recommends that institutions should avail the necessary funds to rollout a comprehensive e-learning training program to address the training related challenges and put up a flourishing ICT infrastructure that can handle the delivery of STEM-based courses. The institutions should consider engaging dedicated e-tutors so that they can dedicate their time to e-learning and put up an effective and efficient e-learning pedagogy. An understanding of these challenges is necessary for e-learning providers, practitioners, policy makers and researchers so that they can put up measures and policies to mitigate them and hence minimize their impact. Finally, these challenges formed the bedrock upon which the larger research was founded whose main aim is to develop an e-learning theory for interaction and collaboration.

\section{Acknowledgements}

The researcher acknowledges the research grant by KCA University and the National Research Fund (NRF) Kenya.

\section{References}

Aldiabat, K. M., \& Le Navenec, C. (2018). Data Saturation: The Mysterious Step in Grounded Theory Method. The Qualitative Report, 23(1), 245-261. https://nsuworks.nova.edu/tqr/vol23/iss1/18

Alzaghoul, A. F. (2012). The Implications of the Learning Theories on Implementing e-Learning Courses. The Research Bulletin of Jordan-ACM, 2(2), 27-30. http://ijj.acm.org/volumes/volume2/issue2/ijjvol2no5.pdf

Amineh, R. J., \& Asl, H. D. (2015). Review of Constructivist and Social Constructivism. Journal of Social Sciences, Literature and Languages, 1(1), 9-16.

https://www.academia.edu/31113252/Review_of_Constructivism_and_Social_Constructivism 
Anderson, T., \& Dron, J. (2011). Three Generations of Distance Education Pedagogy. International Review of Research in Open and Distance Learning, 12(3), 81-97. https://doi.org/10.19173/irrodl.v12i3.890

Aparicio, M., Bacao, F., \& Oliveira, T. (2016). An e-Learning Theoretical Framework. Educational Technology \& Society, 19(1), 292-307.

Arkorful, A., \& Abaidoo, N. (2014). The Role of e-Learning, The Advantages and Disadvantages of Its Adoption in Higher Education. International Journal of Education and Research, 2(12), 397-410. https://doi.org/10.1080/07294360.2014.956693

Bhukuvhani, C., Mupa, M., Mhishi, M., \& Dziva, D. (2012). Science Practical Work Instructional Technologies and Open Distance Learning in Science Teacher Training: A Case Study in Zimbabwe. International Journal of Education and Development using Information and Communication Technology, 8(2), 17-27. https://files.eric.ed.gov/fulltext/EJ1084176.pdf

Bognar, B. (2016). Theoretical Backgrounds of e-Learning. Croatian Journal of Education, 18(1), 225-256. https://doi.org/10.15516/cje.v18i1.1475

Busikova, A., \& Melicherikova, Z. (2013). Ethics in e-Learning. In M.B. Nunes \& M. McPherson (Eds), In Proceedings of IADIS International Conference in e-Learning 2013, (pp. 435-438). http://www.iadisportal.org/e-Learning-2013proceedings

Cercone, K. (2008). Characteristics of Adult Learners with Implications for Online Learning Design. Association for the Advancement of Computing in Education Journal, 16(2), 137-159. https://eric.ed.gov/?id=EJ805727

Charmaz, K. (2014). Constructing Grounded Theory: Introducing Qualitative Methods". Publication Ltd. London. SAGE, pp.1-4. $2^{\text {nd }}$ Edition.

Chun-Tie, Y., Birks, M., \& Francis, K. (2019). Grounded Theory Research: A Design Framework for Novice Researchers. SAGE Open Medicine, 7(0), 1-8. https://doi.org/10.1177/2050312118822927

Commission of University Education. (2017). Universities Authorized to Operate in Kenya (pp. 1-2) CUE.

Dabbagh, N. (2005). Pedagogical Models of e-Learning: A Theory-based Design Framework. International Journal of Technology in Teaching and Learning, 1(1), 25-44.

Foroughi. A. (2015). The Theory of Connectivism: Can it Explain and Guide Learning in the Digital Age? Journal of Higher Education Theory and Practice, 15(5), 11-26. http://t.www.nabusinesspress.com/JHETP/ForoughiA_Web15_5_.pdf

Gentles, S. J., Charles, C., Ploeg, J., \& McKibbon, K. (2015). Sampling in Qualitative Research: Insights from an Overview of the Methods Literature. The Qualitative Report, 20(11), 1772-1789.

Government of Kenya. (2019). Draft National ICT Master Plan 2019-2029. ICT Authority Ministry of Information, Communication and Technology. pp 1-73. August 2019.

Gros, B., \& García-Peñalvo, F. J. (2016). Future Trends in The Design Strategies and Technological Affordances of eLearning. In M. Spector, B. B. Lockee, \& M. D. Childress (Eds.), Learning, Design, and Technology. An International Compendium of Theory, Research, Practice, and Policy (pp. 1-23). Switzerland: Springer International Publishing. https://doi.org/10.1007/978-3-319-17727-4_67-1

Islam, N., Beer, M., \& Slack, F. (2015). e-Learning Challenges Faced by Academics in Higher Education: A Literature Review. Journal of Education and Training Studies, 3(5), 102-112. https://doi.org/10.11114/jets.v3i5.947

Janssen, J., \& Bodemer, D. (2013). Coordinated Computer-Supported Collaborative Learning: Awareness and Awareness Tools. Educational Psychologist, 48(1), 40-55. https://doi.org/10.1080/00461520.2012.749153

Kalpana, T. (2014). A Constructive Perspective on Teaching and Learning: A Conceptual Framework. International Research Journal of Social Sciences, 3(1), 27-29. www.isca.in

Kalpokaite, N., \& Radivojevic, I. (2019). Demystifying Qualitative Data Analysis for Novice Qualitative Researchers. The Qualitative Report, 24(13), 44-57. https://nsuworks.nova.edu/tqr/vol24/iss13/5

Kee, C. L. (2020). Face-to-Face Tutorial, Learning Management System and WhatsApp Group: How Digital Immigrants Interact and Engage in E-learning? Malaysian Online Journal of Educational Technology, 8(1), 18-35. https://doi.org/10.17220/mojet.2020.01.002

Kop, R., \& Hill, A. (2008). Connectivism: Learning Theory of the Future or Vestige of the Past. International Review of Research in Open and Distance Learning, 9(3), 1-13. https://doi.org/10.19173/irrodl.v9i3.523 
Miles, M. B., Huberman, A. M., \& Saldana, J. (2020). Qualitative Data Analysis. A Methods Sourcebook (pp. 40-44). Thousand Oaks, California. SAGE $4^{\text {th }}$ Edition.

Muuro, E. M., Wagacha, P. W., Oboko, R., \& Kihoro, J. (2014). Student Percieved Challenges in Online Collaborative Learning Environment: A Case Study of Higher Learning Institutions in Nairobi, Kenya. International Review of Research in Open and Distance Learning, 15(6), 133-161. http://www.irrodl.org/index.php/irrodl/article/download/1768/3124?inline=1

Mwaniki, E. W., Njihia, S. M., Chege, F. N., \& Ireri, A. M. (2016). Development of Interactive Online Learning Modules: Lessons from Kenyatta University, Kenya. In the Proceedings of the 8th Pan-Commonwealth Forum Open Learning (pp 1-8). Nov 27-30, 2016. Kuala Lumpur, Malaysia http://oasis.col.org/handle/11599/2526

Ndung'u, M. N., Lewis, C., \& Mothobi, O. (2019). The State of ICT in Kenya: After Access. A Policy Paper No. 9. Research ICT Africa. https://researchictafrica.net/2019/07/08/after-access-the-state-of-ict-in-kenya/

Nyerere, J. (2016). Open and Distance Learning in Kenya. A Baseline Survey Report. Common Wealth Of Learning, (pp. 1-23). https://doi.org/10.19173/irrodl.v13i3.1120

Nyerere, J. A., Gravenir, F. Q., \& Mse, G. S. (2012). Delivery of Open Distance and e-Learning in Kenya. International Review of Research in Open and Distance Learning, 13(3), 185-202. http://www.irrodl.org/index.php/irrodl/article/view/1120/2203

Olcott, J. D., Farran, X. C., Echenique, E. G., \& Martínez, J. G. (2015). Ethics and Education in the Digital Age: Global Perspectives and Strategies for Local Transformation on Catalonia. University Knowledge Society Journal, 12(2), 59-72. https://doi.org/10.7238/rusc.v12i2.2455

Raspopovic, M., Jankulovic, A., Runic, J., \& Lucic, V. (2014). Success Factors for E-Learning in Developing Countries: A Case Study of Serbia. International Review of Research in Open and Distance Learning, 15(3), 1-23. https://doi.org/10.19173/irrodl.v15i3.1586

Reay, T., Zafar, A., Monteiro, P., \& Glaser, V. (2019). Presenting Findings from Qualitative Research: One Size Does Not Fit All! Research in The Sociology of Organizations, 59(0), 201-216. https://doi.org/10.1108/S0733$558 \times 20190000059011$

Romero, M. (2011). Distance Learners' Work Life Learning Balance. International Journal of Instructional Technology and Distance Learning, 8(5), 43-48.

https://www.researchgate.net/publication/237012137_Distance_learners'_Work_Life_Learning_Balance

Serdyukova, N., \& Serdyukov, P. (2014). E-Pedagogy: A Model for Online Education. Proceedings of Hawaii Conference 2014: Educational/Instructional Pedagogies, (pp. 1-8). Academic and Business Research Institute (AABRI). http://www.aabri.com/HC2014Manuscripts/HC14024.pdf

Tarus, J. K., Gichoya, D., \& Muumbo, A. (2015). Challenges of Implementing e-Learning in Kenya: A Case of Kenyan Public Universities. International Review of Research in Open and Distance Learning, 16(1), 120-140. https://doi.org/10.19173/irrodl.v16i1.1816

Walsh, I., Holton, J. A., Bailyn, L., Fernandez, W., Levina, N., \& Glaser, B. (2015). What Grounded Theory Is...A Critically Reflective Conversation Among Scholars. Organizational Research Methods. SAGE Journals, pp 1-19. https://doi.org/10.1177/1094428114565028

Weische, M., Jurisch, M. C., Yetton, P. W., \& Krcmar, H. (2017). Gounded Theory Methodology in Information Systems Research. MIS Quarterly, 41(3), 685-701.

https://misq.org/skin/frontend/default/misq/pdf/appendices/2017/V4113Appendices/12382_MA_Wiesche.pdf

Wu, J., Tennyson, R. D., \& Hsia, T. (2010). A Study of Student Satisfaction in Blended e-Learning System Environment. Computer and Education, Elsevier, 55(2010), 155-164. https://doi.org/10.1016/j.compedu.2009.12.012

\section{Copyrights}

Copyright for this article is retained by the author(s), with first publication rights granted to the journal.

This is an open-access article distributed under the terms and conditions of the Creative Commons Attribution license which permits unrestricted use, distribution, and reproduction in any medium, provided the original work is properly cited. 